\title{
MicroRNA Biomarkers for Early Detection of Embryonic Malformations in Pregnancy
}

\author{
Xuezheng $\mathrm{Li}^{1}$ and Zhiyong Zhao ${ }^{2}$
}

${ }^{1}$ Department of Pharmacy, Affiliated Hospital of Yanbian University, Yanji, Jilin, China

${ }^{2}$ Department of Obstetrics, Gynecology and Reproductive Sciences, University of Maryland School of Medicine, Baltimore, Maryland, USA

\begin{abstract}
Congenital birth defects, manifested in newborn infants, are formed during early embryogenesis. Targeted and individualized interventions to prevent birth defects require early detection of risk and signs of developmental abnormalities. Current diagnosis of structural anomalies largely relies on ultrasonography, which can only detect abnormities after their formation in fetuses. Biomolecules, mainly proteins, in maternal blood have been used as indicators of fetal anomalies; however, they lack adequate sensitivity for detecting embryonic malformations. Recently, cell-free microRNAs (miRNAs) have been found in blood and evaluated as biomarkers for diseases. Expression of certain miRNAs in maternal plasma has been shown to be correlated with birth defects in infants. Although their reliability and sensitivity remain to be validated, miRNAs, which can be amplified and sequenced, are potentially sensitive and specific biomarkers for early embryonic dysmorphogenesis.
\end{abstract}

Keywords: miRNA; Birth defect; Embryonic malformation; Diagnosis

\section{Introduction}

Birth defects are a serious public health problem. Every year, nearly 270,000 newborns die and 3.3 million children suffer from congenital anomalies worldwide [1]. In the United States of America, where perinatal care is widely available, about 120,000 babies are born with structural abnormalities [2]. The causes of developmental malformations include genetic and non-genetic factors. Maternal diseases (e.g., diabetes mellitus), clinical drugs (e.g., valproic acid), and environmental factors (e.g., alcohol, pollutants) are among the nongenetic factors ascribed for rapid increases of birth defects [3,4]. Efforts to prevent birth defects have been made at the population level, for example, dietary vitamin supplementation. Individualized and defect type-focused practices require detection and diagnosis of embryonic malformations during early pregnancy.

\section{Embryonic malformations}

Structural defects are most commonly seen in the central nervous and cardiovascular systems (CNS and CVS). In the CNS, anomalies are present in the brain (e.g., exencephaly) and spinal cord (e.g., spina bifida) [5]. These abnormalities are formed due to failure in neural tube closure during the early embryogenesis, thus, referred to as neural tube defects (NTDs) [5]. The process of neural tube formation, namely neurulation, occurs between 18-26 days of post-conception in humans [6]. In the CVS, most common anomalies are associated with abnormal cardiac septation to produce septal defects [7]. These defects are also formed during the early cardiogenesis [7]. Therefore, any measures to prevent birth defects should be implemented before or during the so-called susceptible period of organogenesis, which is the early first trimester.

\section{Diagnosis of embryonic/fetal anomalies}

Detection of embryonic/fetal anomalies in pregnancies largely relies on ultrasonography [8]. With recent technological developments, imaging resolution and processing have been considerably improved [9]. Color Doppler sonography can measure fetal cardiac functions $[10,11]$. However, ultrasonography has limitations in detecting structural abnormalities in young embryos. Most abnormalities are only diagnosed in fetuses older than 12 weeks of gestation $[9,12]$. Very few anomalies can be recognized as young as 10 weeks of gestation [13]. By then, the damages in the fetuses are already irreversible.

\section{Biomarkers for diagnosis of fetal anomalies}

Searching for molecular biomarkers in maternal blood and amniotic fluid has been undertaken for decades. Because of the limited accessibility of the amniotic fluid, maternal blood is the major source of biomarkers.

One class of biomarkers, reflecting maternal physiological conditions, for example, oxidative stress markers (endogenous antioxidants and lipoperoxidation products), have been used to evaluate the risk of developing fetal abnormalities [14,15].

Protein biomarkers, including $\alpha$-fetoprotein, human chorionic gonadotropin, maternal serum unconjugated estriol, and Inhibin-A, have also been characterized and used in diagnosis of fetal anomalies in pregnancies [16-19]. However, these biomarkers can only be used as supplementary indicators to ultrasound examinations because of their low sensitivity and reliability.

\section{MicroRNAs as biomarkers for detection of embryonic malformations}

Recently, nucleic acids (DNA and RNA), especially non-coding RNAs, have been found in human blood and urine [20-23]. Among them, microRNAs (miRNAs) have drawn much attention as potential biomarkers for diseases [22,24,25]. MI RNAs are 22 not single-stranded RNAs, present intracellularly and extracellularly [26-28]. Mi RNAs are

${ }^{*}$ Corresponding author: Zhiyong Zhao, Department of Obstetrics, Gynecology and Reproductive Sciences, University of Maryland School of Medicine, Baltimore, MD 21201, USA, Tel: (410) 706-8401; E-mail: zzhao@fpi.umaryland.edu

Received July 31, 2014; Accepted October 07, 2014; Published October 14, 2014

Citation: Li X and Zhao Z (2014) MicroRNA Biomarkers for Early Detection of Embryonic Malformations in Pregnancy. J Biomol Res Ther 3: 119. doi: 10.4172/2167-7956.1000119

Copyright: (c) $2014 \mathrm{Li} \mathrm{X}$, et al. This is an open-access article distributed under the terms of the Creative Commons Attribution License, which permits unrestricted use, distribution, and reproduction in any medium, provided the original author and source are credited. 
initially synthesized as long primary miRNA (pri-miRNA) molecules by RNA polymerase II or III. Pri-miRNAs are processed by nuclear endoribo nuclease Drosha into 70 nt hairpin structures, known as pre-miRNA. The pre-miRNAs are transported out of the nucleus by Exportin 5. In the cytoplasm, the pre-miRNAs are further processed by another RNase, Dicer, to become 22 not single-stranded miRNAs [29-31]. Within the cell, miRNAs, facilitated by a protein complex, known as RNA-induced silencing complex (RISC) containing argonaute (Ago) proteins, bind to messenger RNAs (mRNAs) via the WaltsonCrick complementary base-pairing to block translation or induce mRNA degradation [32-34].

MiRNAs are expressed in the developing embryo and have been demonstrated to play an important role in embryogenesis [35-37]. Dysregulation of miRNAs has been shown to be associated with human birth defects, e.g., Tetralogy of Fallot in the heart and Di George syndrome [38,39]. Spatial and temporal expression patterns of miRNAs in the developing primitive organs of the embryo, such as the neural fold and heart tube, imply that they are involved in malformations of the structures during the period of organogenesis susceptible to environmental insults [36,40-42]. Animal studies have shown that deficiency in miRNA biogenesis and processing results in abnormal embryogenesis. For example, embryos lacking the dicerl or ago2 genes, or certain species of miRNA (knockouts) fail to develop beyond gastrulation or develop abnormalities in many organ systems, including NTDs and heart defects [43-47], resembling birth defects in humans.

The mechanisms by which miRNAs regulate development remain to be fully delineated. Available data have suggested that miRNAs target genes that regulate neurulation and cardiogenesis, including transcription factors and genes in growth factor signaling (e.g., the TGF $\beta$ and Wnt families) $[36,40,48,49]$.

MiRNAs, are present in the amniotic fluid and potentially used to predict outcome of pregnancy [50,51]. However, invasive methods to collect amniotic fluid during gestation are not practical. MiRNAs are excreted from cells and transported into blood stream (Figure 1 ), and can be obtained from maternal blood samples collected during prenatal care $[22,24]$. MiRNAs are promising biomarkers for early detection of embryonic malformations in pregnancies, for the following reasons. First, miRNAs are very stable in body fluids [23]. Their initial appearance in the blood can indicate the early stages or even before the onset of diseases. Changes in their levels can reliably reflect the progression of diseases. Second, embryonic miRNAs can pass through the maternal-embryonic interface to be present in the maternal system [52,53]. Third, due to the characteristic of base-sequence, certain species of miRNA can provide unique signatures of embryonic conditions. Fourth, technologies to amplify and sequence miRNAs can detect tiny amounts of miRNAs for early diagnosis and provide sequence-specific information [54,55].

Pregnancy-related miRNAs have been isolated from maternal plasma [56-58]. Microarray, sequencing, and quantitative reverse transcription-coupled polymerase chain reaction assays revealed that the expression profiles of miRNAs are correlated with fetal malformations in the CNS and CVS [56,57]. These studies demonstrate the potential application of this approach to diagnosis of fetal anomalies.

More research is needed to validate the reliability and sensitivity of miRNA markers in detecting embryonic malformations [59]. For example, maternal blood samples are usually collected during the secondary and third trimesters [56,57]. However, embryonic malformations occur during the early first trimester [4,60]. MiRNAs expressed during early embryogenesis, the so-called susceptible period

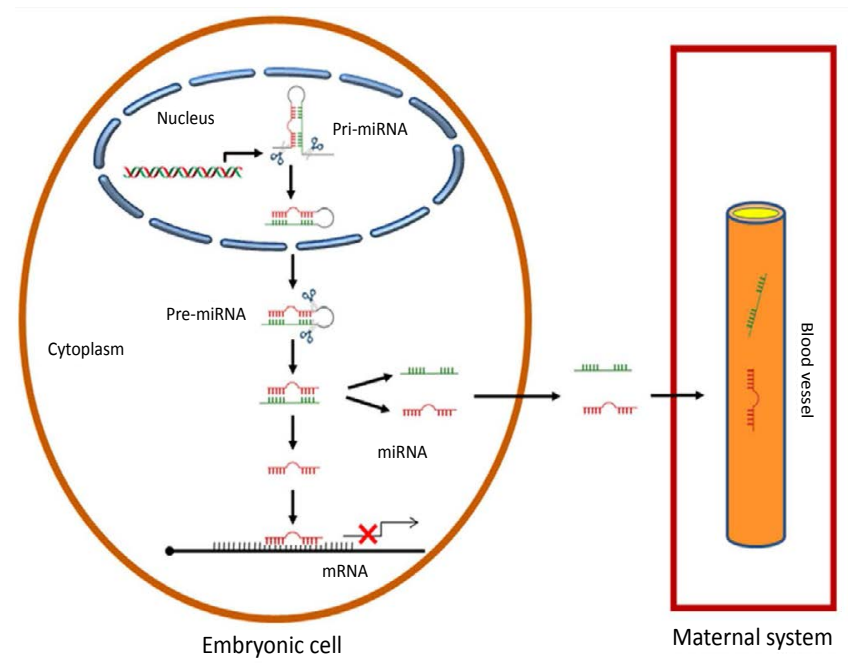

Figure 1: Diagrammatic illustration of embryonic miRNA biogenesis and secretion to maternal circulation. Transcription of miRNA genes generates pre-miRNAs in the nucleus of embryonic cell. pri-miRNAs are processed into pre-miRNAs and transported to the cytoplasm. Pre-miRNAs are cleaved into pre-miRNAs and transported to the cytoplasm. Pre-miRNAs are cleaved
into double-stranded small RNA, and further separated into single-stranded miRNAs. Mi RNAs are either involved in post-transcriptional regulation of mRNAs or secreted into extracellular space and transported into maternal circulation.

of organogenesis, may more reliably reflect the developmental conditions in dysmorphogenesis. Secondly, it is important to distinguish embryonic miRNAs from maternal miRNAs, as they represent different biological processes and may possess different sensitivity. With the recent technologies to amplify and sequence small RNAs, miRNAs can serve as biomarkers to detect risks and early aberrant developmental events in pregnancy, making early diagnosis and individualized birth defect prevention a reality.

\section{Acknowledgement}

Research work of authors' groups was supported by grants from National Science Foundation of China (\#81260102 to X.L.) and the National Institutes of Health of the USA (R01HD076245 and R03HD075995 to Z.Z.). The content is solely the responsibility of the authors and does not necessarily represent the official views of the funding agencies.

\section{References}

1. WHO/CDC/ICBDSR. (2014) Birth defects surveillance: A mannual for programme managers. World Health Organization.

2. Centers for Disease Control and Prevention (CDC) (2008) Update on overall prevalence of major birth defects--Atlanta, Georgia, 1978-2005. MMWR Morb Mortal Wkly Rep 57: 1-5.

3. Finnell RH, Waes JG, Eudy JD, Rosenquist TH (2002) Molecular basis of environmentally induced birth defects. Annu Rev Pharmacol Toxicol 42: 181-208.

4. Zhao Z, Reece EA (2013) New concepts in diabetic embryopathy. Clin Lab Med 33: 207-233.

5. Copp AJ, Greene ND (2010) Genetics and development of neural tube defects. J Pathol 220: 217-230.

6. Greene ND, Stanier P, Copp AJ (2009) Genetics of human neural tube defects Hum Mol Genet 18: R113-129.

7. Poelmann RE, Gittenberger-de Groot AC (2012) Cardiac birth defects Differentiation 84: 1-3.

8. Sonek J (2007) First trimester ultrasonography in screening and detection of fetal anomalies. Am J Med Genet C Semin Med Genet 145C: 45-61.

9. Allan L (2010) Fetal cardiac scanning today. Prenat Diagn 30: 639-643.

10. Sonek J, Nicolaides K (2010) Additional first-trimester ultrasound markers. Clin Lab Med 30: 573-592. 
11. Comas M, Crispi F (2012) Assessment of fetal cardiac function using tissue Doppler techniques. Fetal Diagn Ther 32: 30-38

12. Cameron M, Moran $P$ (2009) Prenatal screening and diagnosis of neural tube defects. Prenat Diagn 29: 402-411.

13. Blaas HG, Eik-Nes SH, Isaksen CV (2000) The detection of spina bifida before 10 gestational weeks using two- and three-dimensional ultrasound. Ultrasound Obstet Gynecol 16: 25-29.

14. Hobbs CA, Cleves MA, Zhao W, Melnyk S, James SJ (2005) Congenital heart defects and maternal biomarkers of oxidative stress. Am J Clin Nutr 82: 598-604.

15. Bogavac M, Lakic N, Simin N, Nikolic A, Sudji J, et al. (2012) Biomarkers of oxidative stress in amniotic fluid and complications in pregnancy. $\mathrm{J}$ Matern Fetal Neonatal Med 25: 104-108.

16. Eunpu DL, Zackai EH, Mennuti MT (1983) Neural tube defects, diabetes, and serum alpha-fetoprotein screening. Am J Obstet Gynecol 147: 729-730.

17. Reece EA, Friedman AM, Copel JA, Kleinman CS (1995) Prenatal diagnosis and management of deviant fetal growth and congenital malformations. In Diabetes Mellitus in Pregnancy, Reece EA, Coustan DR, Eds. New York, Churchill Livingstone 2: 219-249

18. Bahado-Singh RO, Sutton-Riley J (2004) Biochemical screening for congenital defects. Obstet Gynecol Clin North Am 31: 857-872, xi.

19. Bubb JA, Matthews AL (2004) What's new in prenatal screening and diagnosis? Prim Care 31: 561-582, ix.

20. Lo YM, Chiu RW (2012) Genomic analysis of fetal nucleic acids in maternal blood. Annu Rev Genomics Hum Genet 13: 285-306.

21. Su YH, Wang M, Brenner DE, Ng A, Melkonyan H, et al. (2004) Human urine contains small, 150 to 250 nucleotide-sized, soluble DNA derived from the circulation and may be useful in the detection of colorectal cancer. J Mol Diagn 6: 101-107.

22. Etheridge A, Lee I, Hood L, Galas D, Wang K (2011) Extracellular micro RNA a new source of biomarkers. Mutat Res 717: 85-90

23. Van Roosbroeck K, Pollet J, Calin GA (2013) miRNAs and long noncoding RNAs as biomarkers in human diseases. Expert Rev MolDiagn 13: 183-204.

24. Guay C, Regazzi R (2013) Circulating microRNAs as novel biomarkers for diabetes mellitus. Nat Rev Endocrinol 9: 513-521.

25. Baker M (2010) RNA interference: MicroRNAs as biomarkers. Nature 464: 1227.

26. Huang Y, Shen XJ, Zou Q, Wang SP, Tang SM, et al. (2011) Biological functions of microRNAs: a review. J Physiol Biochem 67: 129-139.

27. Bartel DP (2004) MicroRNAs: genomics, biogenesis, mechanism, and function Cell 116: 281-297.

28. Morris KV, Mattick JS2 (2014) The rise of regulatory RNA. Nat Rev Genet 15: 423-437.

29. Ameres SL, Zamore PD (2013) Diversifying microRNA sequence and function. Nat Rev Mol Cell Biol 14: 475-488.

30. Liu Q, Paroo Z (2010) Biochemical principles of small RNA pathways. Annu Rev Biochem 79: 295-319.

31. Siomi H, Siomi MC (2010) Posttranscriptional regulation of microRNA biogenesis in animals. Mol Cell 38: 323-332.

32. Patil VS, Zhou R, Rana TM (2014) Gene regulation by non-coding RNAs. Crit Rev Biochem Mol Biol 49: 16-32.

33. Williams AE (2008) Functional aspects of animal microRNAs. Cell Mol Life Sci 65: $545-562$

34. Peters L, Meister G (2007) Argonaute proteins: mediators of RNA silencing Mol Cell 26: 611-623.

35. Pauli A, Rinn JL, Schier AF (2011) Non-coding RNAs as regulators of embryogenesis. Nat Rev Genet 12: 136-149.

36. Liu N, Olson EN (2010) MicroRNA regulatory networks in cardiovascular development. Dev Cell 18: 510-525

37. Cochella L, Hobert O (2012) Diverse functions of microRNAs in nervous system development. Curr Top DevBiol 99: 115-143

38. Sellier C, Hwang VJ, Dandekar R, Durbin-Johnson B, Charlet-Berguerand $\mathrm{N}$, et al. (2014) Decreased DGCR8 expression and miRNAdysregulation in individuals with 22q11.2 deletion syndrome. PLoS One 9: e103884.
39. Liang D, Xu X, Deng F, Feng J, Zhang H, et al. (2014) miRNA-940 reduction contributes to human Tetralogy of Fallot development. J Cell Mol Med 18 1830-1839.

40. Mukhopadhyay P, Brock G, Appana S, Webb C, Greene RM, et al. (2011) MicroRNA gene expression signatures in the developing neural tube. Birth Defects Res A Clin Mol Teratol 91: 744-762.

41. Krupp DR, Xu PT, Thomas S, Dellinger A, Etchevers HC, et al. (2012) Transcriptome profiling of genes involved in neural tube closure during human embryonic development using long serial analysis of gene expression (longSAGE). Birth Defects Res A Clin Mol Teratol 94: 683-692.

42. Cao L, Kong LP, Yu ZB, Han SP, Bai YF, et al. (2012) microRNA expression profiling of the developing mouse heart. Int J Mol Med 30: 1095-1104.

43. Bernstein E, Kim SY, Carmell MA, Murchison EP, Alcorn H, et al. (2003) Dicer is essential for mouse development. Nat Genet 35: 215-217.

44. Kanellopoulou C, Muljo SA, Kung AL, Ganesan S, Drapkin R, et al. (2005) Dicer-deficient mouse embryonic stem cells are defective in differentiation and centromeric silencing. Genes Dev 19: 489-501.

45. Liu J, Carmell MA, Rivas FV, Marsden CG, Thomson JM, et al. (2004) Argonaute2 is the catalytic engine of mammalian RNAi. Science 305: 1437-1441.

46. Liu N, Bezprozvannaya S, Williams AH, Qi X, Richardson JA, et al. (2008) microRNA-133a regulates cardiomyocyte proliferation and suppresses smooth muscle gene expression in the heart. Genes Dev 22: 3242-3254.

47. Zhao Y, Ransom JF, Li A, Vedantham V, von Drehle M, et al. (2007) Dysregulation of cardiogenesis, cardiac conduction, and cell cycle in mice lacking miRNA-1-2. Cell 129: 303-317.

48. Peng Y, Song L, Zhao M, Harmelink C, Debenedittis P, et al. (2014) Critical roles of miRNA-mediated regulation of TGFî ${ }^{2}$ signalling during mouse cardiogenesis. Cardiovasc Res 103: 258-267.

49. Inui M, Martello G, Piccolo S (2010) MicroRNA control of signal transduction Nat Rev Mol Cell Biol 11: 252-263.

50. Hui L, Wick HC, Edlow AG, Cowan JM, Bianchi DW (2013) Global gene expression analysis of term amniotic fluid cell-free fetal RNA. Obstet Gynecol 121: $1248-1254$

51. Edlow AG, Bianchi DW (2012) Tracking fetal development through molecular analysis of maternal biofluids. Biochim Biophys Acta 1822: 1970-1980.

52. Wessels JM, Edwards AK, Khalaj K, Kridli RT, Bidarimath M, et al. (2013) The microRNAome of pregnancy: deciphering miRNA networks at the maternalfetal interface. PLoS One 8: e72264.

53. Whitehead CL, Teh WT, Walker SP, Leung C, Larmour L, et al. (2013) Circulating MicroRNAs in maternal blood as potential biomarkers for fetal hypoxia in-utero. PLoS One 8: e78487.

54. Stokowy T, Eszlinger M, Åšwierniak M, Fujarewicz K, Jarzb B, et al. (2014) Analysis options for high-throughput sequencing in miRNA expression profiling. BMC Res Notes 7: 144.

55. Gunaratne PH, Coarfa C, Soibam B, Tandon A (2012) miRNA data analysis next-gen sequencing. Methods Mol Biol 822: 273-288.

56. Gu H, Li H, Zhang L, Luan H, Huang T, et al. (2012) Diagnostic role of microRNA expression profile in the serum of pregnant women with fetuses with neural tube defects. J Neurochem 122: 641-649.

57. Zhu S, Cao L, Zhu J, Kong L, Jin J, et al. (2013) Identification of maternal serum microRNAs as novel non-invasive biomarkers for prenatal detection of fetal congenital heart defects. Clin Chim Acta 424: 66-72.

58. Miura K, Miura S, Yamasaki K, Higashijima A, Kinoshita A, et al. (2010) Identification of pregnancy-associated microRNAs in maternal plasma. Clin Chem 56: 1767-1771.

59. Greene ND, Copp AJ (2012) Could microRNAs be biomarkers for neural tube defects? J Neurochem 122: 485-486.

60. Greene ND, Copp AJ (2014) Neural tube defects. Annu Rev Neurosci 37: 221-242. 